\title{
Association of Tumor Necrosis Factor-Alpha-308 G/A and -238 G/A Polymorphism with Diabetic Retinopathy: A Systematic Review and Updated Meta-Analysis
}

\author{
Wenna Gao Ruilin Zhu Liu Yang \\ Department of Ophthalmology, Peking University First Hospital, Beijing, China
}

\author{
Keywords \\ Diabetic retinopathy - Tumor necrosis factor-alpha \\ Polymorphism · Meta-analysis
}

\begin{abstract}
Background: Mounting evidence has suggested that tumor necrosis factor-alpha (TNF-a) can promote the development of diabetic retinopathy (DR), and TNF-a gene variants may influence DR risk. However, the results are quite different. Objectives: To comprehensively address this issue, we performed the meta-analysis to evaluate the association of TNF-a-308 G/A and -238 G/A polymorphism with DR. Method: Data were retrieved in a systematic manner and analyzed using STATA Statistical Software. Crude odds ratios (ORs) with $95 \%$ confidence intervals (Cls) were used to assess the strength of associations. Allelic and genotypic comparisons between cases and controls were evaluated. Results: For the TNF-a-308 G/A polymorphism, overall analysis suggested a marginal association with DR (the OR [95\% CI] of [GA vs. GG], [GA + AA] vs. GG, and [A vs. G] are 1.21 [1.04, 1.41], 1.20 [1.03, $1.39]$, and 1.14 [1.01, 1.30], respectively). And the subgroup analysis indicated an enhanced association among the European population. For the TNF-a-238 G/A polymorphism,
\end{abstract}

karger@karger.com www.karger.com/ore

Karger $\stackrel{\text { ' }}{5}$

BOPEN ACCESS
(C) 2020 The Author(s)

Published by S. Karger AG, Basel

This is an Open Access article licensed under the Creative Commons Attribution-NonCommercial-4.0 International License (CC BY-NC) (http://www.karger.com/Services/OpenAccessLicense), applicable to the online version of the article only. Usage and distribution for commercial purposes requires written permission. there was a mild correlation in the entire group (the OR [95\% $\mathrm{Cl}$ ] of [GA vs. GG] is $1.55[1.14,2.11])$, which was strengthened among the Asian population. Conclusion: The meta-analysis suggested that -308 A and -238 A allele in TNF-a gene potentially increased $D R$ risk and showed a discrepancy in different ethnicities.

(C) 2020 The Author(s)

Published by S. Karger AG, Basel

\section{Introduction}

Vascular complications are related to the hazards of diabetes mellitus (DM), which is an increasingly common metabolic disease and one of the significant resources of crippling diseases. It is widely accepted that diabetic retinopathy (DR), a progressive microvascular complication of DM, occurs in about $18.5 \%-34.6 \%$ individuals with diabetes, especially among patients from 60 to 69 years old, and the risk grew sharply with the duration of DM $[1,2]$.

In the presence of sustained hyperglycemia, pathological changes to retinal microvasculature are caused by a cascade of events involving the formation of advanced glycation end products $[3,4]$. Secondary to the binding of glycation end products to their corresponding receptors
Correspondence to:

Liu Yang, lucy02114@163.com 
anchored on the surface of immune cells and endothelial cells, various proinflammatory cytokines, including tumor necrosis factor-alpha (TNF- $\alpha$ ), are synthetized and secreted [3]. It was reported that TNF- $\alpha$ was mainly involved in the destruction of the blood retinal barrier and the formation of new blood vessels [5]. The research conducted by Yao et al. [6] suggested that the expression of TNF- $\alpha$ in DR patients was significantly distinct from that in healthy controls, and inhibition of TNF has shown promising outcomes in preventing the progression of DR in the mice diabetic model [7]. Therefore, TNF- $\alpha$ serves as a critical element in the pathogenesis of DR.

TNF gene is located on the 6 chromosome in the human leukocyte antigen class III region. Genetic variations in its promoter region may regulate the production of TNF. Contrasting with the limitation of studies concerning other mutants, such as rs1799724 and rs11574936, rs 1800629 and rs361525, where the guanine $(G)$ is substituted by the adenine (A) at positions -308 and -238 , respectively, are 2 TNF- $\alpha$ promoter variants being the most extensively studied. Individuals homozygous for the less common TNF- $\alpha-308$ A allele have also been shown to have higher circulating TNF- $\alpha$ levels than those homozygous for the $G$ allele and have worse outcomes in response to infectious diseases [8-10]. As a result, numerous studies have attempted to investigate whether there is a certain association between TNF- $\alpha-308$ G/A and/or -238 G/A polymorphism and DR risk. However, those results remain conflicting. Although related meta-analyses have been published [11-13], more researches have been carried out in recent years. To address this issue and derive a more precise estimation, we conduct this systematic review and updated meta-analysis to discuss if the association has ethnic disparity or is biased by the classification of DM.

\section{Methods}

\section{Search Strategy}

In this systematic review, a comprehensive literature research was conducted in the database of PubMed, Embase, Ovid Medline, ISI Web of Knowledge, and the China National Knowledge Internet (to May 11, 2020) using research terms including "diabetic retinopathy," "diabetic retinopathies," "DR," "tumor necrosis factor-alpha," "tumor necrosis factor alpha," "tumor necrosis factor," "tumor necrosis factor- $a$," “TNF-alpha," “TNF- $a$," “TNF," "polymorphism, genetic," "polymorphism," "genotype," "single nucleotide polymorphism," "variant," "variation," "allele," "mutation," and the combined phrases to acquire all genetic studies on the relationship between TNF- $\alpha$ $308 \mathrm{G} / \mathrm{A}$ and/or $-238 \mathrm{G} / \mathrm{A}$ polymorphism and the risk of DR. There was no language limitation. We also searched references of original studies or reviews on this topic to identify additional studies. Moreover, we have registered this study on the Prospero Website with the registration number of CRD42020189022.

\section{Inclusion and Exclusion Criteria}

Two authors screened trials independently and discussed with a third author when inconsistencies occurred. Studies were included in accordance with the following criteria: only case-control studies referring to the association between TNF- $\alpha-308$ G/A and/ or $-238 \mathrm{G} / \mathrm{A}$ polymorphism and DR were included, and for the meta-analysis, studies included must also contain the detailed and correct numbers of different genotypes for estimating an odds ratio (OR) with a $95 \%$ confidence interval (CI). When several publications reported on the same population data, the largest or the most complete study was selected.

\section{Quality Assessment}

The methodological quality of included case-control studies was evaluated based on the Newcastle-Ottawa Scale (NOS). Two authors assessed the quality independently, and divergence was arbitrated by a third author. According to the scores of 1-3, 4-6, and 7-9, eligible literatures were categorized as low-, intermediate-, and high-quality researches, respectively.

\section{Data Extraction}

Two investigators assessed articles for inclusion or exclusion independently, resolved disagreements, and attained consistency. For each eligible study, the following information was recorded: the first author's name, the year of publication, ethnicity, type of $\mathrm{DM}$, genotyping methods, the number of patients with DR or without DR (DWR), sex ratio, average age, mean DM duration, and the distribution of each TNF- $\alpha$ genotype. Both proliferative $\mathrm{DR}$ (PDR) and nonproliferative DR (NPDR) were classified as DR. Different ethnicities were divided into the European and the Asian, and DM type was sorted into type $1 \mathrm{DM}$ (T1DM) and type $2 \mathrm{DM}$ (T2DM). We contacted corresponding authors for missing data.

\section{Statistical Analysis}

The strength of the relationship between TNF- $\alpha-308$ G/A and/ or $-238 \mathrm{G} / \mathrm{A}$ polymorphism and DR risk was estimated by calculating pooled ORs with $95 \%$ CIs. We evaluated the risk using the codominant model (AA vs. GG; GA vs. GG), the dominant model ([GA + AA] vs. GG), the recessive model (AA vs. [GG + GA]), and the allelic model (A allele vs. $G$ allele). Hardy-Weinberg equilibrium (HWE) was tested by the $\chi^{2}$ test. If genotype distributions in the controls of all studies are in agreement with HWE, the sensitivity analysis will not be undertaken. If not, the sensitivity analysis will be performed by omitting 1 study at a time to assess the stability of the meta-analysis results. Between-study heterogeneity was appraised by the inconsistency index $I^{2}$ statistic (ranging from 0 to $100 \%)$. Heterogeneity was considered significant if $I^{2}>50 \%$, in which case the random-effects model (the Dersimonian-Laird method) was performed to pool the data. Otherwise, the fixed-effects model (the Mantel-Haenszel method) was used. Studies were categorized into subgroups based on ethnicity and the type of DM. Begg's funnel plot and Egger's test were undertaken to assess publication bias $(p<0.05$ was considered as a representative of statistical significance). All statistical analyses were performed using the STATA Statistical Software (v.12.0; StataCorp, LP, College Station, TX, USA). 


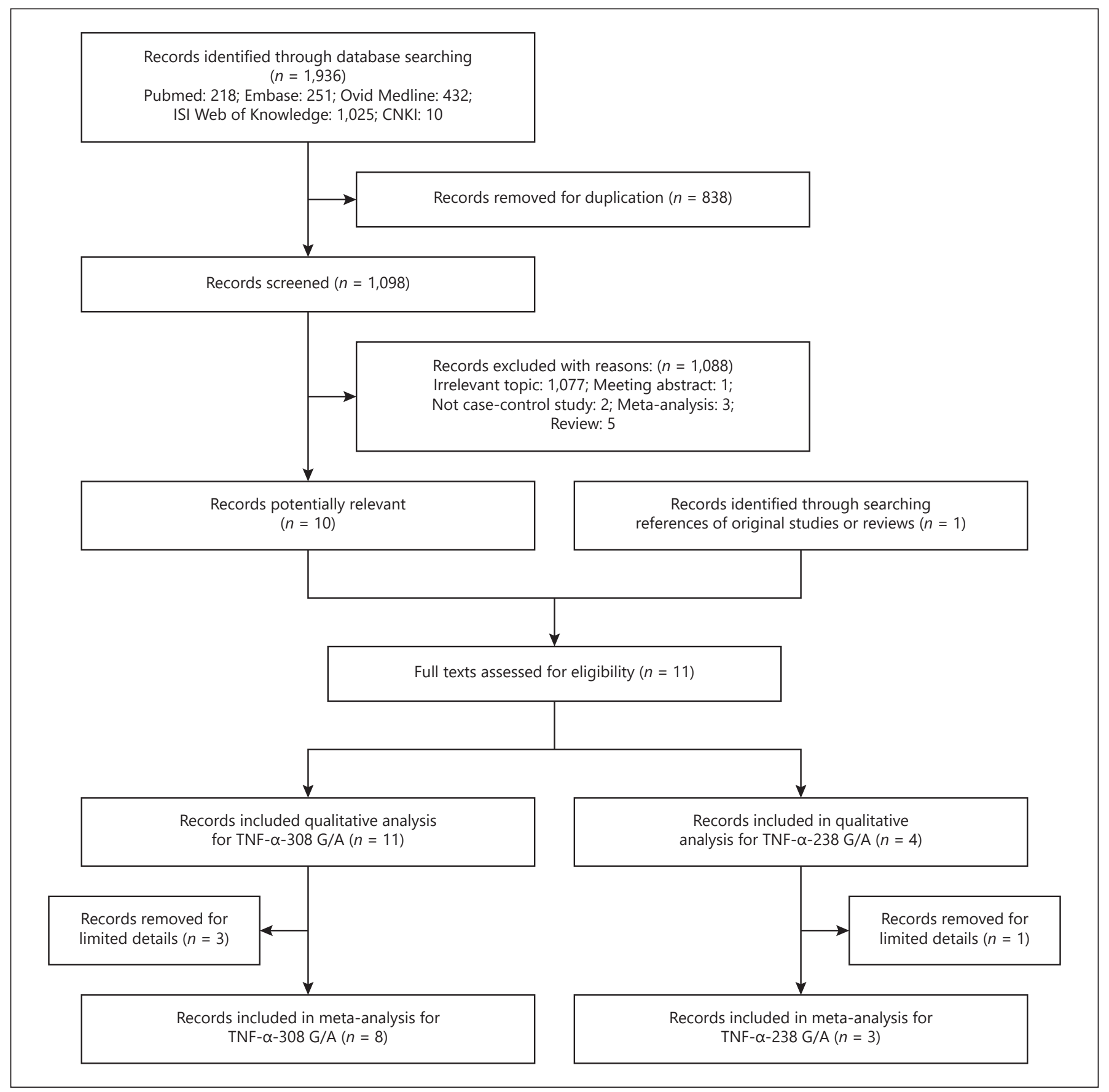

Fig. 1. Flowchart of included studies. TNF- $\alpha$, tumor necrosis factor-alpha; CNKI, China National Knowledge Internet.

\section{Results}

\section{Eligible Studies}

A flowchart of the literature search, according to the Preferred Reporting Items for Systematic Reviews and Meta-Analyses guidelines, is shown in Figure 1. In total,
11 case-control studies were selected in our systematic review [14-24], all of which were referred to TNF- $\alpha-308$ G/A polymorphism and 4 of which were related to TNF- $\alpha-238$ G/A polymorphism $[16,17,20,21]$. Owing to the insufficient information about the distribution of genotypes in several studies [14-16], there were only 8 
case-control studies including 1,698 cases (DR) and 2,064 controls (DWR) [17-24] and 3 case-control studies including 659 cases and 576 controls [17, 20, 21], which correlate with TNF- $\alpha-308$ G/A and TNF- $\alpha-238$ G/A polymorphism, respectively, were included in the meta-analysis.

\section{Characteristics of the Studies and Data Analysis}

The main characteristics of 11 studies included in the systematic review were shown in Table 1 . The quality evaluation of included studies by Newcastle-Ottawa Scale suggested that all of studies had high quality, except the study conducted by Bućan et al. [21] in 2009 which had intermediate quality. On the TNF- $\alpha-308$ G/A polymorphism side, there were 6 studies of the Asians and 5 studies of the Europeans among these eligible publications. Ten studies were related to T2DM compared with 4 studies for T1DM, since 3 of them referred to both T1DM and T2DM. Ten studies showed no association between TNF- $\alpha-308$ G/A polymorphism and DR in spite of the ethnicity or DM type, while a case-control study in Brazil concerning the European T2DM subjects proved TNF- $\alpha-308$ A allele was in connection with an increased risk of PDR [17]. In the matter of TNF- $\alpha-238$ G/A polymorphism, 1 study of the Asians and 3 studies of the Europeans were included. Three studies were related to T2DM, while 2 studies were in association with T1DM, since 1 of them referred to both T1DM and T2DM. The findings of 3 studies did not indicate any association between TNF- $\alpha-238$ G/A polymorphism and DR, while that of 1 study connected with the Asian T2DM patients stated that TNF- $\alpha-238$ A was a potent hazard factor for the occurrence of PDR.

For the further quantitative analysis, the related data of these studies were shown in Table 2. Among studies investigating the TNF- $\alpha-308$ G/A polymorphism, the methods for genotyping included real-time polymerase chain reaction (PCR), PCR-sequence-specific primers, amplification refractory mutation system-polymerase chain reaction, PCR-restriction fragment length polymorphism method, allele-specific PCR, and Taq-PCR. Besides, only the study conducted by Bućan et al. [21] in 2009 having a deviation from HWE in the controls of those studies. And for the TNF- $\alpha-238$ G/A polymorphism, the methods for genotyping involve real-time PCR, amplification refractory mutation system-PCR, and PCR-restriction fragment length polymorphism method. The control of the study is conducted by Sesti et al. [17] in 2015 deviating from HWE.

\section{Meta-Analysis}

The main results of the meta-analysis and the heterogeneity test are shown in Table 3. For the TNF- $\alpha-308$ G/A polymorphism, the results showed that no significant heterogeneity was detected in each model. Overall, we found a marginally statistical significant association between the allele A and DR risk in overall population (for GA vs. GG: OR 1.21, 95\% CI 1.04-1.41; for [GA + AA] vs. GG: OR 1.20, 95\% CI 1.03-1.39; for A vs. G: OR 1.14, 95\% CI 1.01-1.30). And in reference to the TNF- $\alpha-238$ G/A polymorphism, significant heterogeneity existed among all the models, apart from the codominant model (GA vs. GG). Besides, a mild correlation was found in the entire group (for GA vs. GG: OR 1.55, 95\% CI 1.14-2.11).

\section{Subgroup Analysis}

In the case of TNF- $\alpha-308$ G/A polymorphism, significantly increased risks were observed among the European population in the subgroup analysis by ethnicity (for GA vs. GG: OR 1.27, 95\% CI 1.06-1.51; for [GA + AA] vs. GG: OR 1.25, 95\% CI 1.05-1.49; for A vs. G: OR 1.17, 95\% CI 1.01-1.36; shown in Table 3). In the stratified analysis by the type of DM, the TNF- $\alpha$ variation was not found associated with elevated DR risk in either T1DM patients or T2DM patients in any model (shown in Table 3). And when it comes to the TNF- $\alpha-238$ G/A polymorphism, every model's heterogeneity was eliminated when the subgroup analysis was made according to ethnicity (for each model, $I^{2}=0.0$ ), but remained no change by DM type. Therefore, it was the factor, ethnicity, that accounted for the heterogeneity of included studies (shown in Table 3). What's more, the susceptibility of DR enhanced among the Asian population (for AA vs. GG: OR 5.79, 95\% CI 2.47-13.57; for GA vs. GG: OR 1.91, 95\% CI 1.29-2.83; for [GA + AA] vs. GG: OR 2.30, 95\% CI 1.58-3.33; for AA vs. [GA + GG]: OR 4.65, 95\% CI 2.01-10.77; for A vs. G: OR 2.29, 95\% CI 1.68-3.12; shown in Table 3). What's more, in the subgroup analysis by DM type, except for the model GA versus GG which indicated low coherence between TNF- $\alpha-238$ G/A and T2DM (OR 1.55, 95\% CI 1.13-2.11), no significant relationship was examined.

\section{Sensitivity Analysis}

Given the study not conforming to HWE, we performed the sensitivity analysis. With regard to the TNF- $\alpha-308$ G/A polymorphism, when the study conducted by Bućan et al. [21] in 2009 was removed, the pooled ORs did not change substantially in all comparison models, and it represented the good stability and reliability of outcomes of the meta-analysis (shown in 
Table 1. Main characteristics of case-control studies included in the systematic review

\begin{tabular}{|c|c|c|c|c|c|c|c|}
\hline First author & Ethnicity & $\begin{array}{l}\text { DM } \\
\text { type }\end{array}$ & $\begin{array}{l}\text { Sample } \\
\text { sizes }\end{array}$ & $\begin{array}{l}\text { Age, } \\
\text { years }\end{array}$ & $\begin{array}{l}\text { DM duration, } \\
\text { years }\end{array}$ & $\begin{array}{l}\text { Association } \\
\text { with DR }\end{array}$ & $\begin{array}{l}\text { NOS } \\
\text { score }\end{array}$ \\
\hline $\begin{array}{l}T N F-\alpha-308 G / A \\
\text { Fan et al. }[14]\end{array}$ & Asian & $\mathrm{T} 2$ & $\begin{array}{l}314 \\
255\end{array}$ & - & $\begin{array}{l}13.0 \pm 8.0 \\
14.7 \pm 6.0\end{array}$ & No & 8 \\
\hline \multirow[t]{2}{*}{ Wang et al. [15] } & Asian & $\mathrm{T} 1$ & $\begin{array}{l}120 \\
100\end{array}$ & $58.6 \pm 15.2$ & $15.2 \pm 6.6$ & No & 7 \\
\hline & & $\mathrm{T} 2$ & $\begin{array}{l}120 \\
100\end{array}$ & $61.2 \pm 16.6$ & $18.4 \pm 7.4$ & No & 7 \\
\hline \multirow[t]{2}{*}{ Kaidonis et al. [16] } & European & $\mathrm{T} 1$ & $\begin{array}{l}340^{*} \\
260\end{array}$ & $\begin{array}{l}- \\
-\end{array}$ & $\begin{array}{l}- \\
-\end{array}$ & No & 8 \\
\hline & & $\mathrm{T} 2$ & $\begin{array}{l}993^{*} \\
901\end{array}$ & $\begin{array}{l}- \\
-\end{array}$ & $\begin{array}{l}- \\
-\end{array}$ & No & 8 \\
\hline Rodrigues et al. [18] & European & $\mathrm{T} 2$ & $\begin{array}{l}66 \\
36\end{array}$ & $\begin{array}{l}56.6 \pm 8.5 \\
52.8 \pm 9.2\end{array}$ & $\begin{array}{l}17.3 \pm 9.2 \\
8.8 \pm 7.7\end{array}$ & No & 7 \\
\hline Sikka et al. [19] & Asian & $\mathrm{T} 2$ & $\begin{array}{l}162 \\
300\end{array}$ & $\begin{array}{l}58.9 \pm 7.5 \\
59.4 \pm 9.7^{*}\end{array}$ & $\begin{array}{l}13.3 \pm 7.2 \\
10.1 \pm 7.8\end{array}$ & No & 7 \\
\hline Paine et al. [20] & Asian & $\mathrm{T} 2$ & $\begin{array}{l}253 \\
240\end{array}$ & $\begin{array}{l}52.0 \pm 15.0 \\
54.0 \pm 12.0\end{array}$ & $\begin{array}{l}16.0 \pm 6.0 \\
17.0 \pm 7.0\end{array}$ & No & 8 \\
\hline Bućan et al. [21] & European & $\mathrm{T} 1$ & $\begin{array}{l}19 \\
28\end{array}$ & $30.8 \pm 13.8^{*}$ & $13.9 \pm 9.1^{*}$ & No & 6 \\
\hline Lindholm et al. [22] & European & $\mathrm{T} 1$ & $\begin{array}{l}315 \\
307\end{array}$ & $38.2 \pm 13.6^{*}$ & $18.1 \pm 15.6^{*}$ & No & 7 \\
\hline \multirow[t]{2}{*}{$\begin{array}{l}T N F-\alpha-238 \text { G/A } \\
\text { Kaidonis et al. [16] }\end{array}$} & European & $\mathrm{T} 1$ & $\begin{array}{l}340^{*} \\
260\end{array}$ & - & $\begin{array}{l}- \\
-\end{array}$ & No & 8 \\
\hline & & $\mathrm{T} 2$ & $\begin{array}{l}993^{*} \\
901\end{array}$ & - & - & No & 8 \\
\hline Sesti et al. [17] & European & $\mathrm{T} 2$ & $\begin{array}{l}387 \\
308\end{array}$ & $\begin{array}{l}61.6 \pm 9.3^{*} \\
59.9 \pm 9.6^{*}\end{array}$ & $\begin{array}{l}14.8 \pm 8.8^{*} \\
11.8 \pm 7.0^{*}\end{array}$ & No & 7 \\
\hline Paine et al. [20] & Asian & $\mathrm{T} 2$ & $\begin{array}{l}253 \\
240\end{array}$ & $\begin{array}{l}52.0 \pm 15.0 \\
54.0 \pm 12.0\end{array}$ & $\begin{array}{l}16.0 \pm 6.0 \\
17.0 \pm 7.0\end{array}$ & Yes & 8 \\
\hline Bućan et al. [21] & European & $\mathrm{T} 1$ & $\begin{array}{l}19 \\
28\end{array}$ & $30.8 \pm 13.8^{*}$ & $13.9 \pm 9.1^{*}$ & No & 6 \\
\hline
\end{tabular}

Data are displayed as mean \pm standard deviation. In each item, the upper line represents the DR group, while the lower line represents the DWR group. DM, diabetes mellitus; NOS, Newcastle-Ottawa Scale; -, not available; DR, patients with diabetic retinopathy; DWR, patients without diabetic retinopathy. ${ }^{*}$ Estimated values. 
Table 2. Description of key data for studies included in the meta-analysis

\begin{tabular}{|c|c|c|c|c|c|c|c|c|}
\hline \multirow[t]{2}{*}{ First author } & \multirow{2}{*}{$\begin{array}{l}\text { Genotyping } \\
\text { methods }\end{array}$} & \multirow{2}{*}{$\begin{array}{l}\text { Sex ratio } \\
(\mathrm{M} / \mathrm{F})\end{array}$} & \multicolumn{5}{|c|}{ Genotypes } & \multirow[t]{2}{*}{ HWE } \\
\hline & & & GG & GA & AA & G & A & \\
\hline \multicolumn{9}{|l|}{$T N F-\alpha-308 G / A$} \\
\hline \multirow[t]{2}{*}{ Sesti et al. [17] } & Real-time PCR & $(223,181)$ & 284 & 108 & 12 & 676 & 132 & \multirow{2}{*}{0.49} \\
\hline & & $(137,185)$ & 251 & 68 & 3 & 570 & 74 & \\
\hline \multirow[t]{2}{*}{ Rodrigues et al. [18] } & PCR-SSP & $(15,51)$ & 49 & 17 & 0 & 115 & 17 & \multirow{2}{*}{0.35} \\
\hline & & $(4,32)$ & 29 & 6 & 1 & 64 & 8 & \\
\hline \multirow[t]{2}{*}{ Sikka et al. [19] } & ARMS-PCR & $(-,-)$ & 142 & 19 & 1 & 303 & 21 & \multirow{2}{*}{0.84} \\
\hline & & $(-,-)$ & 263 & 36 & 1 & 562 & 38 & \\
\hline \multirow[t]{2}{*}{ Paine et al. [20] } & ARMS-PCR & $(133,120)$ & 165 & 77 & 11 & 407 & 99 & \multirow{2}{*}{0.69} \\
\hline & & $(128,112)$ & 161 & 70 & 9 & 392 & 88 & \\
\hline \multirow[t]{2}{*}{ Bućan et al. [21] } & PCR-RFLP & $(-,-)$ & 11 & 7 & 1 & 29 & 9 & \multirow{2}{*}{0.02} \\
\hline & & $(-,-)$ & 20 & 5 & 3 & 45 & 11 & \\
\hline \multirow{4}{*}{ Lindholm et al. [22] } & Real-time PCR & $(-,-)$ & 145 & 154 & 16 & 444 & 186 & \multirow{2}{*}{0.15} \\
\hline & & $(-,-)$ & 154 & 134 & 19 & 442 & 172 & \\
\hline & & $(-,-)$ & 200 & 85 & 10 & 485 & 105 & \multirow{2}{*}{0.51} \\
\hline & & $(-,-)$ & 379 & 179 & 25 & 937 & 229 & \\
\hline \multirow[t]{2}{*}{ Wang et al. [23] } & Taq-PCR & $(-,-)$ & 94 & 15 & 0 & 203 & 15 & \multirow{2}{*}{0.23} \\
\hline & & $(-,-)$ & 63 & 8 & 1 & 134 & 10 & \\
\hline \multirow[t]{2}{*}{ Yoshioka et al. [24] } & AS-PCR & $(39,36)$ & 74 & 1 & 0 & 149 & 1 & \multirow{2}{*}{0.88} \\
\hline & & $(115,61)$ & 172 & 4 & 0 & 348 & 4 & \\
\hline \multirow{3}{*}{$\begin{array}{l}T N F-\alpha-238 G / A \\
\text { Sesti et al. [17] }\end{array}$} & & & & & & & & \multirow{3}{*}{0.02} \\
\hline & Real-time PCR & $(212,175)$ & 347 & 38 & 2 & 732 & 42 & \\
\hline & & $(133,175)$ & 277 & 28 & 3 & 582 & 34 & \\
\hline \multirow[t]{2}{*}{ Paine et al. [20] } & ARMS-PCR & $(133,120)$ & 130 & 92 & 31 & 352 & 154 & \multirow{2}{*}{0.69} \\
\hline & & $(128,112)$ & 170 & 63 & 7 & 403 & 77 & \\
\hline \multirow[t]{2}{*}{ Bućan et al. [21] } & PCR-RFLP & $(-,-)$ & 17 & 2 & 0 & 36 & 2 & \multirow{2}{*}{0.84} \\
\hline & & $(-,-)$ & 26 & 2 & 0 & 54 & 2 & \\
\hline
\end{tabular}

In each item, the upper line represents the DR group, while the lower line represents the DWR group. M, male; F, female; HWE, Hardy-Weinberg equilibrium; PCR, polymerase chain reaction; PCR-SSP, PCR-sequence-specific primers; ARMS-PCR, amplification refractory mutation system PCR; PCR-RFLP, PCR restriction fragment length polymorphism method; ASPCR, allele-specific PCR; DR, patients with diabetic retinopathy; DWR, patients without diabetic retinopathy.

Fig. 2a-e). Similarly, as for the TNF- $a-238$ G/A polymorphism, when the study of Sesti et al. [17] was omitted, the results also did not have any qualitative alteration, which indicated that the results of this meta-analysis were basically stable and robust (shown in Fig. $2 \mathrm{f}-\mathrm{j}$ ).

\section{Publication Bias}

On the part of TNF- $a-308$ G/A polymorphism, the Begg's funnel plot appeared symmetric (shown in Fig. 3ae), and the Egger's test supported that there was no significant statistical evidence of publication bias for genetic models AA versus GG, GA versus GG (GA + AA) versus GG, AA versus (GG + GA), and A versus $G$ model, with the $p$ values of $0.293,0.805,1.000,0.293$, and 0.621 , respectively. In terms of TNF- $\alpha-238$ G/A polymorphism, from the Begg's funnel plot of models GA versus GG and $(G A+A A)$ versus $G G$, studies included were within the range of CIs, while those of models AA versus GG, AA versus $(G G+G A$ ), and $A$ versus $G$ were not (shown in Fig. 3f-j). However, the Egger's test showed no publication bias for any of 5 genetic models, with the $p$ values of $0.317,0.602,0.602,0.317$, and 0.602 , respectively. 
Table 3. Summary of odds ratios and $95 \%$ confidence intervals of TNF- $\alpha-308$ G/A and - 238 G/A polymorphism and diabetic retinopathy risk

\begin{tabular}{|c|c|c|c|c|}
\hline Comparisons & $\begin{array}{l}\text { Studies, } \\
n\end{array}$ & OR $(95 \% \mathrm{CI})$ & $I^{2}(\%)$ & $\begin{array}{l}\text { Alleles/genotypes } \\
\text { (DR/DWR) }\end{array}$ \\
\hline \multicolumn{5}{|c|}{$T N F-\alpha-308$ G/A } \\
\hline \multicolumn{5}{|l|}{ AA versus GG } \\
\hline Total & 8 & $1.08(0.73,1.58)$ & 2.1 & $2,769(1,215 / 1,554)$ \\
\hline \multicolumn{5}{|l|}{ Ethnicity } \\
\hline European & 4 & $1.07(0.69,1.66)$ & 40.2 & $1,612(728 / 884)$ \\
\hline Asian & 4 & $1.08(0.48,2.45)$ & 0.0 & $1,157(487 / 670)$ \\
\hline \multicolumn{5}{|l|}{ Type of DM } \\
\hline $\mathrm{T} 1$ & 2 & $0.87(0.44,1.69)$ & 0.0 & $369(173 / 196)$ \\
\hline T2 & 7 & $1.10(0.69,1.77)$ & 21.1 & $2,400(1,042 / 1,358)$ \\
\hline \multicolumn{5}{|l|}{ GA versus GG } \\
\hline Total & 8 & $1.21(1.04,1.41)$ & 0.0 & $3,649(1,647 / 2,002)$ \\
\hline \multicolumn{5}{|l|}{ Ethnicity } \\
\hline European & 4 & $1.27(1.06,1.51)$ & 0.0 & $2,285(1,060 / 1,225)$ \\
\hline Asian & 4 & $1.05(0.78,1.42)$ & 0.0 & $1,364(587 / 777)$ \\
\hline \multicolumn{5}{|l|}{ Type of DM } \\
\hline T1 & 2 & $1.27(0.93,1.74)$ & 5.4 & $630(317 / 313)$ \\
\hline $\mathrm{T} 2$ & 7 & $1.10(0.92,1.31)$ & 0.0 & $3,019(1,330 / 1,689)$ \\
\hline \multicolumn{5}{|c|}{$(\mathrm{GA}+\mathrm{AA})$ versus $\mathrm{GG}$} \\
\hline \multirow{2}{*}{\multicolumn{5}{|c|}{ Ethnicity }} \\
\hline & & & & \\
\hline European & 4 & $1.25(1.05,1.49)$ & 0.0 & $2,375(1,099 / 1,276)$ \\
\hline Asian & 4 & $1.05(0.79,1.41)$ & 0.0 & $1,387(599 / 788)$ \\
\hline \multicolumn{5}{|l|}{ Type of DM } \\
\hline $\mathrm{T} 1$ & 2 & $1.21(0.89,1.64)$ & 0.0 & $669(334 / 335)$ \\
\hline \multirow{2}{*}{\multicolumn{5}{|c|}{ AA versus $(G A+G G)$}} \\
\hline & & & & \\
\hline Total & 8 & $1.00(0.69,1.47)$ & 5.7 & $3,762(1,698 / 2,064)$ \\
\hline \multicolumn{5}{|l|}{ Ethnicity } \\
\hline European & 4 & $0.99(0.64,1.52)$ & 42.0 & $2,375(1,099 / 1,276)$ \\
\hline Asian & 4 & $1.06(0.47,2.39)$ & 0.0 & $1,387(599 / 788)$ \\
\hline \multicolumn{5}{|l|}{ Type of DM } \\
\hline T1 & 2 & $0.77(0.40,1.49)$ & 0.0 & $669(334 / 335)$ \\
\hline $\mathrm{T} 2$ & 7 & $1.09(0.68,1.75)$ & 15.6 & $3,093(1,364 / 1,729)$ \\
\hline \multicolumn{5}{|l|}{ A versus $G$} \\
\hline Total & 8 & $1.14(1.01,1.30)$ & 0.0 & $7,524(3,396 / 4,128)$ \\
\hline \multicolumn{5}{|l|}{ Ethnicity } \\
\hline European & 4 & $1.17(1.01,1.36)$ & 14.4 & $4,750(2,198 / 2,552)$ \\
\hline Asian & 4 & $1.05(0.81,1.36)$ & 0.0 & $2,774(1,198 / 1,576)$ \\
\hline \multicolumn{5}{|l|}{ Type of DM } \\
\hline T1 & 2 & $1.09(0.86,1.38)$ & 0.0 & $1,338(668 / 670)$ \\
\hline $\mathrm{T} 2$ & 7 & $1.09(0.93,1.27)$ & 17.0 & $6,186(2,728 / 3,458)$ \\
\hline \multicolumn{5}{|c|}{ TNF- $\alpha-238 \mathrm{G} / A$} \\
\hline \multicolumn{5}{|l|}{ AA versus GG } \\
\hline Total & 3 & $2.01(0.20,20.56)$ & 82.0 & $1,010(527 / 483)$ \\
\hline \multicolumn{5}{|l|}{ Ethnicity } \\
\hline European & 2 & $0.53(0.09,3.21)$ & 0.0 & $672(366 / 306)$ \\
\hline Asian & 1 & $5.79(2.47,13.57)$ & 0.0 & $338(161 / 177)$ \\
\hline \multicolumn{5}{|l|}{ Type of DM } \\
\hline $\mathrm{T} 1$ & 1 & Excluded & - & $43(17 / 26)$ \\
\hline T2 & 2 & $2.01(0.20,20.56)$ & 82.0 & $967(510 / 457)$ \\
\hline GA versus GG & & & & \\
\hline Total & 3 & $1.55(1.14,2.11)$ & 32.3 & $1,192(626 / 566)$ \\
\hline
\end{tabular}


Table 3 (continued)

\begin{tabular}{|c|c|c|c|c|}
\hline Comparisons & $\begin{array}{l}\text { Studies, } \\
n\end{array}$ & OR $(95 \% \mathrm{CI})$ & $I^{2}(\%)$ & $\begin{array}{l}\text { Alleles/genotypes } \\
\text { (DR/DWR) }\end{array}$ \\
\hline \multicolumn{5}{|l|}{ Ethnicity } \\
\hline European & 2 & $1.11(0.67,1.82)$ & 0.0 & $737(404 / 333)$ \\
\hline Asian & 1 & $1.91(1.29,2.83)$ & 0.0 & $455(222 / 233)$ \\
\hline \multicolumn{5}{|l|}{ Type of DM } \\
\hline $\mathrm{T} 1$ & 1 & $1.53(0.20,11.92)$ & 5.4 & $47(19 / 28)$ \\
\hline $\mathrm{T} 2$ & 2 & $1.55(1.13,2.11)$ & 66.1 & $1,145(607 / 538)$ \\
\hline \multicolumn{5}{|c|}{$(\mathrm{GA}+\mathrm{AA})$ versus $\mathrm{GG}$} \\
\hline Total & 3 & $1.57(0.80,3.07)$ & 69.1 & $1,235(659 / 576)$ \\
\hline \multicolumn{5}{|l|}{ Ethnicity } \\
\hline European & 2 & $1.05(0.65,1.70)$ & 0.0 & $742(406 / 336)$ \\
\hline Asian & 1 & $2.30(1.58,3.33)$ & 0.0 & $493(253 / 240)$ \\
\hline \multicolumn{5}{|l|}{ Type of DM } \\
\hline $\mathrm{T} 1$ & 1 & $1.53(0.20,11.92)$ & 0.0 & $47(19 / 28)$ \\
\hline $\mathrm{T} 2$ & 2 & $1.57(0.71,3.43)$ & 84.5 & $1,188(640 / 548)$ \\
\hline \multicolumn{5}{|c|}{ AA versus $(\mathrm{GA}+\mathrm{GG})$} \\
\hline Total & 3 & $1.82(0.22,15.04)$ & 78.4 & $1,235(659 / 576)$ \\
\hline \multicolumn{5}{|l|}{ Ethnicity } \\
\hline European & 2 & $0.53(0.09,3.18)$ & 0.0 & $742(406 / 336)$ \\
\hline Asian & 1 & $4.65(2.01,10.77)$ & 0.0 & $493(253 / 240)$ \\
\hline \multicolumn{5}{|l|}{ Type of DM } \\
\hline $\mathrm{T} 1$ & 1 & Excluded & - & $47(19 / 28)$ \\
\hline $\mathrm{T} 2$ & 2 & $1.82(0.22,15.04)$ & 78.4 & $1,188(640 / 548)$ \\
\hline \multicolumn{5}{|l|}{ A versus $G$} \\
\hline Total & 3 & $1.53(0.74,3.15)$ & 77.4 & $2470(1,318 / 1,152)$ \\
\hline \multicolumn{5}{|l|}{ Ethnicity } \\
\hline European & 2 & $1.00(0.64,1.58)$ & 0.0 & $1,484(812 / 672)$ \\
\hline Asian & 1 & $2.29(1.68,3.12)$ & 0.0 & $986(506 / 480)$ \\
\hline \multicolumn{5}{|l|}{ Type of DM } \\
\hline $\mathrm{T} 1$ & 1 & $1.50(0.20,11.14)$ & 0.0 & $94(38 / 56)$ \\
\hline $\mathrm{T} 2$ & 2 & $1.53(0.67,3.50)$ & 88.7 & $2,376(1,280 / 1,096)$ \\
\hline
\end{tabular}

OR, odds ratio; TNF- $\alpha$, tumor necrosis factor-alpha; DM, diabetes mellitus; DR, patients with diabetic retinopathy; DWR, patients without diabetic retinopathy; CI, confidence interval.

\section{Discussion}

Unraveling genes that contribute to the pathogenic risk of DR has been one of the major foci of basic researches in DR over the past few decades. A growing number of putative genes and genetic variants have been discussed to detect the genetic risk loci associated with DR $[25,26]$. However, the relationship between TNF- $\alpha$ polymorphism and the presence and progression of DR remained unclear due to controversial findings generated by several relatively small studies. Consequently, we are intended to discuss this issue in depth.

Relevance of TNF- $\alpha-308$ G/A Polymorphism and DR

The earliest investigation covering the theme of TNF- $\alpha-308$ G/A polymorphism and DR risk was report- ed by Wang et al. [27]. However, owing to the failure of reporting the genotype distribution of TNF- $\alpha-308$ G/A polymorphism in DR and DWR patients, it is impossible to determine whether there is a correlation between them. Our systematic review covered 11 available relevant researches and revealed that compared with 10 studies arguing no linkage between TNF- $\alpha-308$ G/A polymorphism and DR whatever the ethnicity or DM type is, 1 study recruiting the European T2DM subjects suggested that -308 A allele might raise the morbidity of PDR. Next, the meta-analysis included 8 studies involving 1,698 DR cases and 2,064 controls. Under the codominant model (GA vs. GG), the dominant model ([GA + AA] vs. GG), and the allelic model (A allele vs. $G$ allele), all summary ORs indicated that TNF- $\alpha-308$ G/A polymorphism was marginally significantly associated with an increased risk 


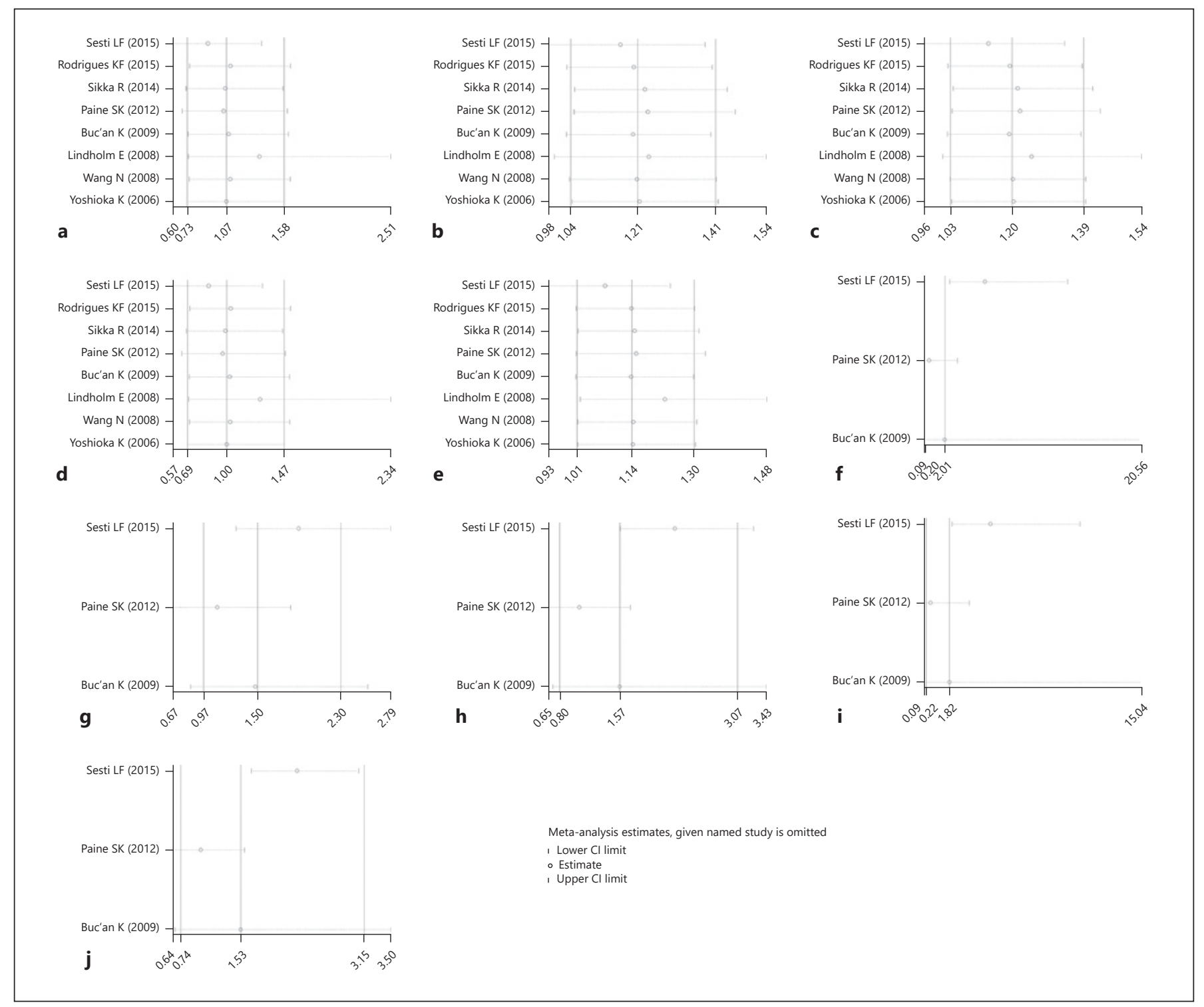

Fig. 2. Sensitivity analyses to explore the influence of the individual dataset to the pooled ORs. a-e The models of AA versus GG, GA versus GG (GA + AA) versus GG, AA versus (GG + GA) and A versus $G$ about the TNF- $\alpha-308$ G/A polymorphism, respectively. $\mathbf{f}-\mathbf{j}$ Those of the TNF- $\alpha-238$ G/A polymorphism, respectively. OR, odds ratio; TNF- $\alpha$, tumor necrosis factor-alpha; CI, confidence interval.

of DR. Because differences in ethnic groups, which bring out different genetic backgrounds, might affect genetic predispositions to human diseases [28], the subgroups were based on ethnicity. In the stratified analysis, significant differences were observed with the European ethnicity, while not among the Asian population. In addition, there was evidence suggesting that rs 1800629 was found a consistent association with the risk of T1DM [29], but not with T2DM [30]. As a result, we further explored the difference in the separate analyses of T1DM and T2DM.
However, the finding implied the lack of a relationship between this polymorphism and the type of DM. What's more, it should be noted that the genetic distributions of the controls in the study conducted by Bućan et al. [21] in 2009 deviated from HWE, indicating the possibility of bias. Thus, we conducted the sensitivity analyses to omit the study. Results from the pooled ORs before and after omitting the study deviating from HWE were similar, suggesting that the result was little affected by the study. Furthermore, no significant publication bias was ob- 

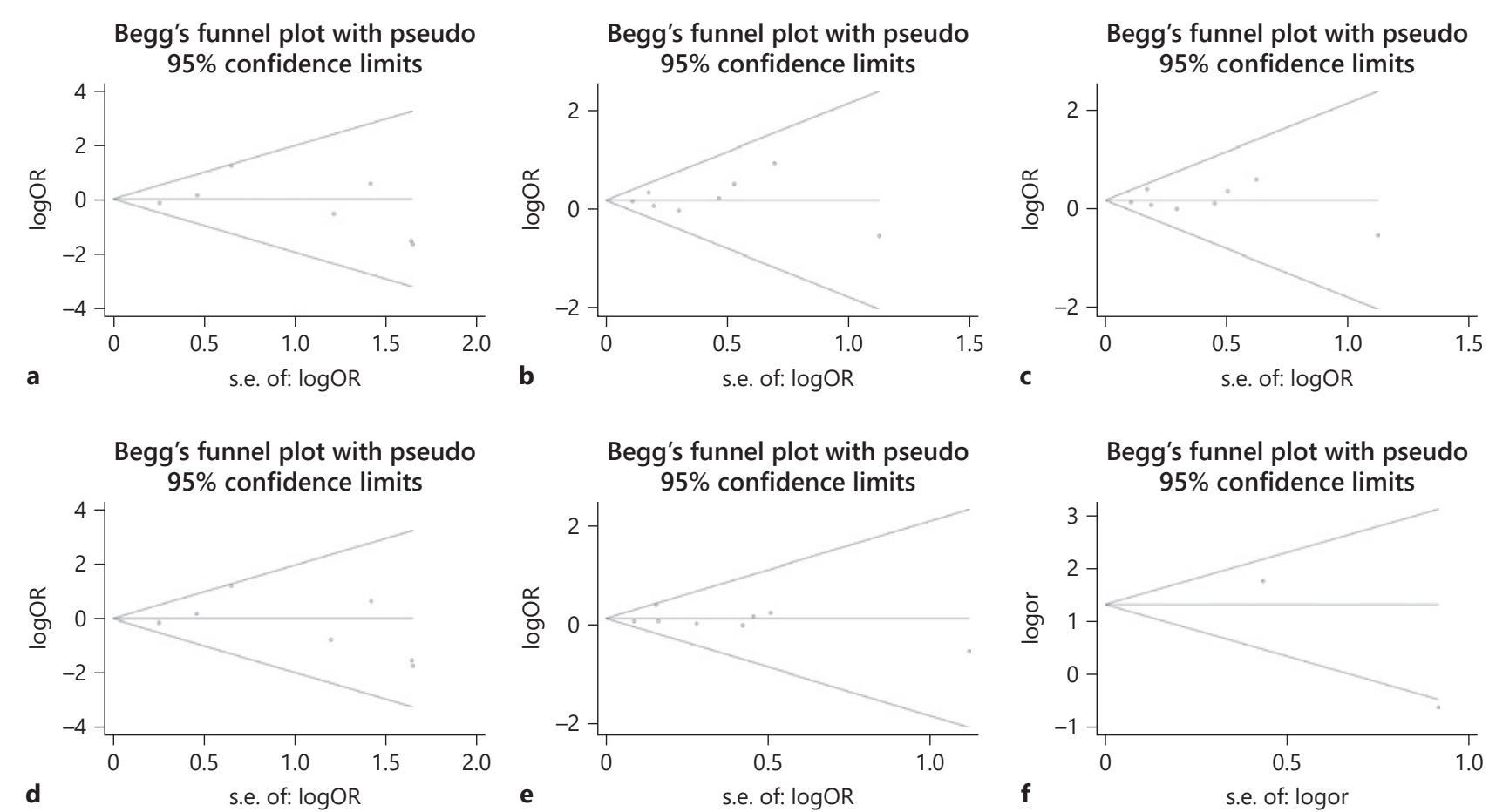

Begg's funnel plot with pseudo $95 \%$ confidence limits
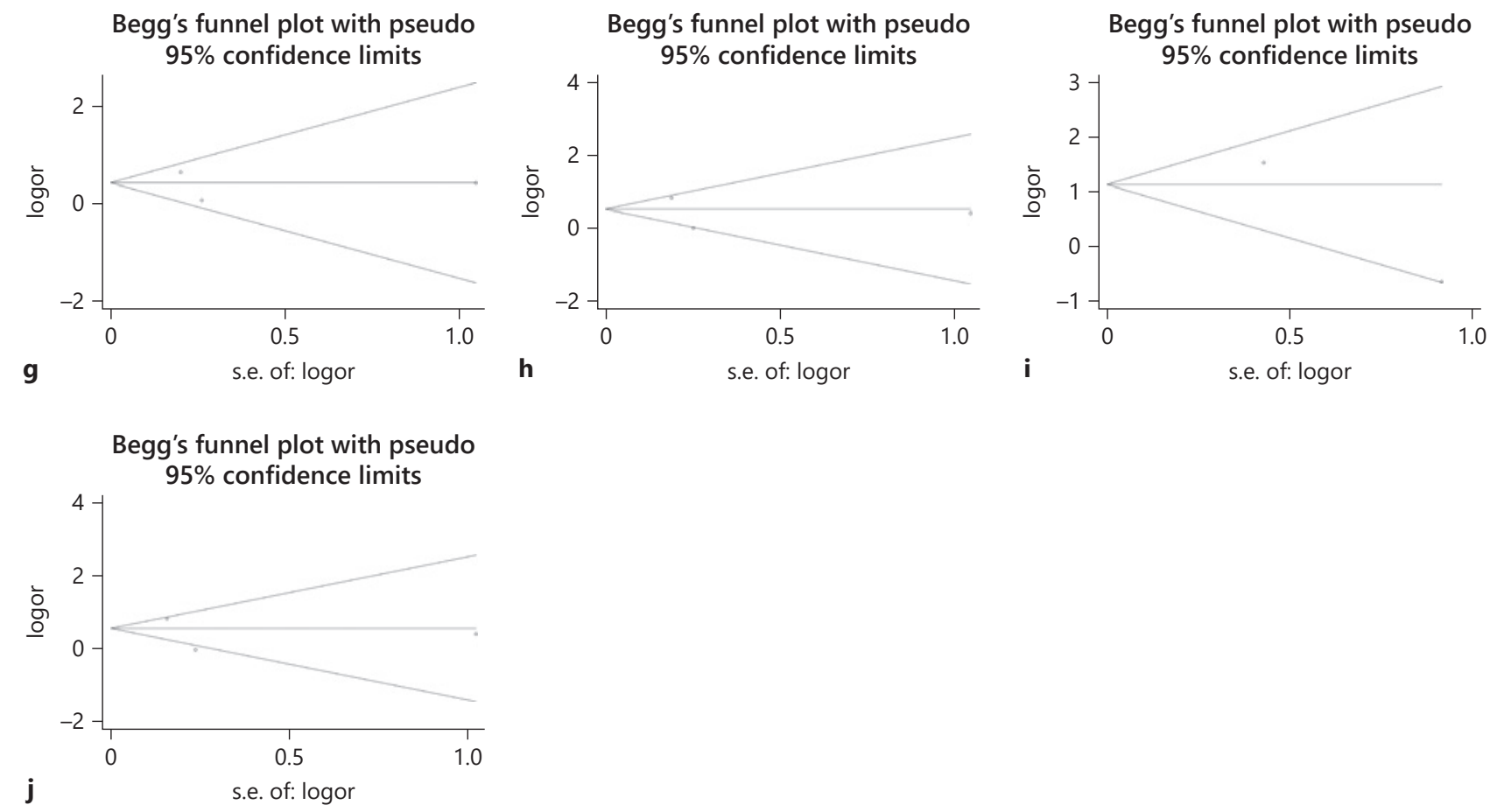

Fig. 3. Funnel plot of the meta-analysis of TNF- $\alpha$ polymorphism and risk for diabetic retinopathy. a-e The models of AA versus GG, GA versus GG, (GA + AA) versus GG, AA versus (GG + GA), and A versus G about the TNF- $\alpha-308$ G/A polymorphism, respectively. $\mathbf{f}-\mathbf{j}$ Those of the TNF- $\alpha-238$ G/A polymorphism, respectively. TNF- $\alpha$, tumor necrosis factor-alpha; OR, odds ratio. 
served in the pooled results in any genetic model, demonstrating the robustness of our meta-analysis.

Previously, meta-analyses conducted by Liu et al. [11] and Meng et al. [13] showed that there was no obviously statistical relevancy between DR and TNF- $\alpha-308$ G/A polymorphism in global and/or subgroup analyses by DM type and ethnicity. In our meta-analysis, 2 extra studies were included, and that might explain why marginal significance was detected among the European population. Besides, some studies also focused on the issue that whether there is a relationship between TNF- $\alpha$ polymorphism and different stages of DR, such as NPDR and PDR. For example, Sesti et al. [17] found that although having no difference between the NPDR subjects and DWR subjects, the genetic frequency of -308 A polymorphism in PDR subjects was more than that of DWR subjects. Then, this was upheld by the achievements of Fan and his colleagues [12]. However, there were also studies deeming no significant association between this promoter polymorphism and different DR phenotypes [15]. Further, on the basis of the divergence about the microaneurysms turnover and the central retinal thickness, Simões et al. [31] stratified 307 NPDR patients of T2DM into 3 different phenotypes, and by massively genotyping single nucleotide polymorphisms of several candidate genes where TNF- $\alpha-308$ G/A was comprised, they still did not discover any definite correlation between the variant and NPDR.

Unexpectedly, while the findings of our research suggested an enhanced association between rs1800629 and DR in the European population, Liu et al. [11] observed a stronger connection between rs 1800629 and diabetic nephropathy (DN), another major complication of DM, in the Asian population. The ethnic difference in the susceptibility to DR and DN of rs1800629 may need a further in-depth study.

\section{Relevance of TNF- $\alpha-238$ G/A Polymorphism and DR}

Four researches were retrieved for the qualitative analysis. Among them, 3 articles suggested that TNF- $\alpha-238$ G/A was irrelevant with DR in both T1DM and T2DM, and 1 study found certain association between -238 A allele and PDR. Further, 3 studies involving 659 DR cases and 576 controls were included for the meta-analysis. Under the codominant model (GA vs. GG), the summary OR demonstrated a mild correlation between TNF- $\alpha-238$ G/A variant and DR. Similar to rs1800629, there was also ethnic disparity about the pathogenicity of rs361525 in some diseases [32]. Thus, the subgroup analysis based on ethnicity was performed. On one hand, heterogeneity among studies included descended sharply, which proved

TNF-Alpha Polymorphism and Diabetic Retinopathy that ethnic differences could lead to the deviation of the results and may account for the sources of heterogeneity. On the other hand, statistical correlations were observed among the Asian population in all analysis models, suggesting that -238 A carriers might have a high risk of DR in Asian subjects. Besides, there were evidences that functions of the variant might vary depending on the type of DM $[33,34]$. Therefore, we next discussed the effect of T1DM and T2DM. Neither heterogeneity among included studies nor the general results appeared any marked change. So we concluded that DM type had no notable effect on the findings. Furthermore, though the control's genotype distribution in the study of Sesti et al. [17] did not comply with HWE, the sensitivity analysis proved that it would not alter the ultimate result strikingly. Meanwhile, no remarkable publication bias was detected in the pooled results for any analysis model, which strengthened the reliability of our meta-analysis.

Similarly, there were also a few of studies exploring the relationship between TNF- $\alpha-238$ G/A polymorphism and various degrees of DR. Sesti et al. [17] reported that the -238 $\mathrm{G}$ and $\mathrm{A}$ allele frequencies in NPDR patients were not significantly distinct with those of DWR patients. Unlike the variant of rs 1800629 , the meta-analysis published by Fan et al. [12] did not find any correlation between rs361525 and DR in total or in the PDR subgroup. The reason for such a difference might be due to the difference of analysis models adopted. The meta-analysis of Fan et al. only used 3 analysis models, namely the dominant model ([GA + AA] vs. GG), the recessive model (AA versus $[G G+G A]$ ), and the allelic model (A allele vs. G allele). By contrast, not only those models but also the codominant models (AA vs. GG, GA vs. GG) were undertaken in our meta-analysis. And it was just the codominant model (GA vs. GG) that demonstrated the association between TNF- $\alpha-238$ G/A polymorphism and DR. Consequently, in case of missing some potential findings, it is necessary to perform comprehensive analyses. What is more, 1 extra study was also included in our meta-analysis.

However, reports about the relationship between TNF- $\alpha-238$ G/A polymorphism and DN are still limited. Therefore, there may be a need to carry out the relevant research.

\section{Issues Remaining}

Several inadequacies exist in our meta-analysis, and there is still much left to be improved. To begin with, in our meta-analysis, the accurate disease durations, ages, and classifications of DR for individual patients, which can matter much in the final conclusions, are unavailable. For example, relevant researches have showed that the predisposi- 
tion to immunity stimuli among the elderly often has to do with altered gene frequencies of some inflammatory factors, such as TNF- $\alpha$ [35], and sex can also play a vital role in the association between TNF and certain diseases [36]. As a result, it is essential to investigate the relationship of TNF- $\alpha$ polymorphism and DR risk in different age and/or gender groups. Next, it merits attention that several studies are not in line with HWE. This may heighten the selection bias in the controls, although sensitivity analyses have suggested the high stability of our meta-analysis's conclusions. Afterward, this meta-analysis was limited by the small sample size - especially for the TNF- $\alpha-238$ G/A polymorphism - though Egger's tests testify no publication bias. Finally, we have not carried out in-depth explorations on some potential gene-gene interactions. For example, $\mathrm{Ku}-$ mar et al. [33] ascertained that among Indian patients, it is the linkage disequilibrium between TNF- $\alpha-308$ G/A and -238 G/A and particular HLA-DR3-DQ2 haplotypes that results in the associations of them with T1DM. Those discrepancies indicate the need to implement rigorous quality control procedures in future studies.

\section{Conclusions}

Our systematic review suggests that TNF- $\alpha$ polymorphism may be associated with elevated DR risk in DM patients, especially TNF- $\alpha-308$ G/A polymorphism in the European population and TNF- $\alpha-238$ G/A polymorphism in the Asian population. Because of the small sample size and the limitations of our study, future larger scale epidemiological investigation of this topic should be conducted to validate our findings.

\section{Acknowledgments}

This meta-analysis has received an enthusiastic support from some authors, who provided us several necessary details about their research. The researchers we would like to show their sincere appreciation to are as follows: Prof. Kátia Santos, Laboratory of Human Molecular Genetics, Universidade Luterana do Brasil (ULBRA), Canoas, Brazil and Cardiology Division, Hospital de Clínicas de Porto Alegre (HCPA), Porto Alegre, Brazil; Prof. José Cunha-Vaz, Prof. Conceição Lobo, and Dr. Joana Ecsodi, Association for Innovation and Biomedical Research on Light and Image (AIBILI), Coimbra, Portugal; Prof. Karina Gomes, Departamento de Análises Clínicas e Toxicológicas, Faculdade de Farmácia, Universidade Federal de Minas Gerais, Belo Horizonte, MG, Brazil; Prof. A.J.S. Bhanwer, Department of Human Genetics, Guru Nanak Dev University, Amritsar, Punjab, India. Besides, we also thank Prof. Jicheng Lv, Department of Nephrology, Peking University First Hospital, Beijing, China, for guidance to extract essential details.

\section{Statement of Ethics}

Our paper only makes a secondary analysis of published studies and does not include the original overview of clinical trials, and ethical approval is not required. Thus, in our paper, the ethical statement is not included. In addition, we have registered this study on the Prospero Website with the registration ID of CRD42020189022.

\section{Conflict of Interest Statement}

The authors have no conflicts of interest to declare.

\section{Funding Sources}

The work was supported by the National Natural Science Foundation of China (Grant No. 81670841).

\section{Author Contributions}

Yang Liu contributed to the idea and design of this study and revised the manuscript. Both Wenna Gao and RuiLin Zhu carried out the screening procedure and data extraction. Besides, Wenna Gao participated in the design of the study, performed the statistical analysis, and drafted the manuscript. Ruilin Zhu revised the manuscript, helped to improve the English language, and gave some suggestions to the manuscript. All authors read and approved the final manuscript.

\section{Data Availability Statement}

The data that support the findings of this study are available from the corresponding author upon reasonable request.

References

Ophthalmic Res 2021;64:903-915 DOI: $10.1159 / 000513586$
1 Song $\mathrm{P}, \mathrm{Yu}$ J, Chan KY, Theodoratou E, Rudan I. Prevalence, risk factors and burden of diabetic retinopathy in China: a systematic review and meta-analysis. J Glob Health. 2018 Jun;8(1):010803.

2 Yau JW, Rogers SL, Kawasaki R, Lamoureux EL, Kowalski JW, Bek T, et al. Global prevalence and major risk factors of diabetic retinopathy. Diabetes Care. 2012 Mar;35(3):55664.

3 Feng Y, Gross S, Chatterjee A, Wang Y, Lin J, Hammes HP. Transcription of inflammatory cytokine TNFa is upregulated in retinal angiogenesis under hyperoxia. Cell Physiol Biochem. 2016;39(2):573-83.

4 Capitao M, Soares R. Angiogenesis and inflammation crosstalk in diabetic retinopathy. J Cell Biochem. 2016 Nov;117(11):2443-53. 
5 Kaidonis G, Abhary S, Daniell M, Gillies M, Fogarty R, Petrovsky N, et al. Genetic study of diabetic retinopathy: recruitment methodology and analysis of baseline characteristics. Clin Exp Ophthalmol. 2014 Jul;42(5):486-93.

6 Yao Y, Li R, Du J, Li X, Zhao L, Long L, et al. Tumor necrosis factor- $\alpha$ and diabetic retinopathy: review and meta-analysis. Clinica Chimica Acta. 2018;485:210-7.

7 Cahoon JM, Rai RR, Carroll LS, Uehara H, Zhang X, O'Neil CL, et al. Intravitreal AAV2. COMP-Ang1 prevents neurovascular degeneration in a murine model of diabetic retinopathy. Diabetes. 2015 Dec;64(12):4247-59.

8 Tang GJ, Huang SL, Yien HW, Chen WS, Chi $\mathrm{CW}, \mathrm{Wu} \mathrm{CW}$, et al. Tumor necrosis factor gene polymorphism and septic shock in surgical infection. Crit Care Med. 2000 Aug; 28(8):2733-6.

9 Louis E, Franchimont D, Piron A, Gevaert Y, Schaaf-Lafontaine N, Roland S, et al. Tumour necrosis factor (TNF) gene polymorphism influences TNF-alpha production in lipopolysaccharide (LPS)-stimulated whole blood cell culture in healthy humans. Clin Exp Immunol. 1998 Sep;113(3):401-6.

10 Bouma G, Crusius JB, Oudkerk Pool M, Kolkman JJ, von Blomberg BM, Kostense PJ, et al. Secretion of tumour necrosis factor alpha and lymphotoxin alpha in relation to polymorphisms in the TNF genes and HLA-DR alleles. Relevance for inflammatory bowel disease. Scand J Immunol. 1996 Apr;43(4):456-63.

11 Liu M, Shang M, Wang Y, Li Q, Liu X, Yang L, et al. Effects of TNF-alpha-308G/A polymorphism on the risk of diabetic nephropathy and diabetic retinopathy: an updated meta-analysis. Horm Metab Res. 2020 Oct;52(10):724.

12 Fan WY, Liu NP. Association between candidate gene polymorphisms and diabetic retinopathy: meta-analysis. Ophthalmol CHN. 2019;28(3):222-8.

13 Meng N, Zhang Y, Li H, Ma J, Qu Y. Association of tumor necrosis factor alpha promoter polymorphism (TNF-alpha $238 \mathrm{G} / \mathrm{A}$ and TNF-alpha $308 \mathrm{G} / \mathrm{A}$ ) with diabetic mellitus, diabetic retinopathy and diabetic nephropathy: a meta-analysis. Curr Eye Res. 2014 Feb; 39(2):194-203.

14 Fan WY, Gu H, Yang XF, She CY, Liu XP, Liu NP. Association of candidate gene polymorphisms with diabetic retinopathy in Chinese patients with type 2 diabetes. Int J Ophthalmol. 2020;13(2):301-8.

15 Wang J, Wang X, Jiang ZX, Bao N, Liu H, Tao LM. The correlation between tumor necrosis factor gene polymorphism and diabetic retinopathy. Biomed Res. 2018;29(4):684-8.

16 Kaidonis G, Craig JE, Gillies MC, Abhary S, Essex RW, Chang JH, et al. Promoter poly- morphism at the tumour necrosis factor/lymphotoxin-alpha locus is associated with type of diabetes but not with susceptibility to sightthreatening diabetic retinopathy. Diab Vasc Dis Res. 2016;13(2):164-7.

17 Sesti LF, Crispim D, Canani LH, Polina ER, Rheinheimer J, Carvalho PS, et al. The $-308 \mathrm{G}>$ a polymorphism of the TNF gene is associated with proliferative diabetic retinopathy in Caucasian Brazilians with type 2 diabetes. Invest Ophthalmol Vis Sci. 2015;56(2): 1184-90.

18 Rodrigues KF, Pietrani NT, Sandrim VC, Vieira CM, Fernandes AP, Bosco AA, et al. Association of a large panel of cytokine gene polymorphisms with complications and comorbidities in type 2 diabetes patients. J Diabetes Res. 2015;2015:605965

19 Sikka R, Raina P, Matharoo K, Bandesh K, Bhatia R, Chakrabarti S, et al. TNF- $\alpha$ (g. -308 $\mathrm{G}>\mathrm{A}$ ) and ADIPOQ (g. $+45 \mathrm{~T}>\mathrm{G}$ ) gene polymorphisms in type 2 diabetes and microvascular complications in the region of Punjab (North-West India). Curr Eye Res. 2014; 39(10):1042-51.

20 Paine SK, Sen A, Choudhuri S, Mondal LK, Chowdhury IH, Basu A, et al. Association of tumor necrosis factor $\alpha$, interleukin 6 , and interleukin 10 promoter polymorphism with proliferative diabetic retinopathy in type 2 diabetic subjects. Retina. 2012;32(6):1197203.

21 Bućan K, Ivanisević M, Zemunik T, Boraska V, Skrabić V, Vatavuk Z, et al. Retinopathy and nephropathy in type 1 diabetic patients: association with polymorphysms of vitamin D-receptor, TNF, Neuro-D and IL-1 receptor 1 genes. Coll Antropol. 2009 Dec;33(Suppl 2): 99-105.

22 Lindholm E, Bakhtadze E, Cilio C, Agardh E, Groop L, Agardh CD. Association between LTA, TNF and AGER polymorphisms and late diabetic complications. PloS One. 2008; 3(6): 2546

23 Wang N, Huang K, Zou H, Shi Y, Zhu J, Tang W, et al. No association found between the promoter variants of TNF-alpha and diabetic retinopathy in Chinese patients with type 2 diabetes. Curr Eye Res. 2008;33(4): 377-83.

24 Yoshioka K, Yoshida T, Takakura Y, Umekawa T, Kogure A, Toda H, et al. Relationship between polymorphisms $804 \mathrm{C} / \mathrm{A}$ and $252 \mathrm{~A} / \mathrm{G}$ of lymphotoxin-alpha gene and -308G/A of tumor necrosis factor alpha gene and diabetic retinopathy in Japanese patients with type 2 diabetes mellitus. Metabolism. 2006;55(10): 1406-10.

25 Liu E, Kaidonis G, McComish BJ, Gillies MC, Abhary S, Essex RW, et al. MicroRNA-related genetic variants are associated with diabetic retinopathy in type 1 diabetes mellitus. Invest Ophthalmol Vis Sci. 2019 Sep 3;60(12):393742.

26 Graham PS, Kaidonis G, Abhary S, Gillies MC, Daniell M, Essex RW, et al. Genomewide association studies for diabetic macular edema and proliferative diabetic retinopathy. BMC Med Genet. 2018 May 8;19(1):71.

27 Wang Y, Ng MC, So WY, Ma R, Ko GT, Tong $\mathrm{PC}$, et al. Association between tumour necrosis factor-alpha G-308A polymorphism and risk of nephropathy in obese Chinese type 2 diabetic patients. Nephrol Dial Transplant. 2005 Dec;20(12):2733-8.

28 Song D, Cheng D. Associations of TNFa308G/A and TNFa-238G/A polymorphisms with ischemic stroke in East Asians and nonEast Asians: a meta-analysis. Genet Test $\mathrm{Mol}$ Biomarkers. 2017;21(1):10-6.

29 Timasheva YR, Balkhiyarova ZR, Nasibullin TR, Avzaletdinova DS, Morugova TV, Mustafina $\mathrm{OE}$, et al. Multilocus associations of inflammatory genes with the risk of type $1 \mathrm{dia}-$ betes. Gene. 2019 Jul 30;707:1-8.

30 Boraska V, Rayner NW, Groves CJ, Frayling TM, Diakite M, Rockett KA, et al. Large-scale association analysis of TNF/LTA gene region polymorphisms in type 2 diabetes. BMC Med Genet. 2010 May 6;11:69.

31 Simões MJ, Lobo C, Egas C, Nunes S, Carmona S, Costa MÂ, et al. Genetic variants in ICAM1, PPARGC1A and MTHFR are potentially associated with different phenotypes of diabetic retinopathy. Ophthalmologica. 2014; 232(3):156-62.

32 Kumar P, Misra S, Kumar A, Pandit AK, Chakravarty K, Prasad K. Association between tumor necrosis factor-alpha $(-238 \mathrm{G} / \mathrm{A}$ and $-308 \mathrm{G} / \mathrm{A}$ ) gene polymorphisms and risk of ischemic stroke: a meta-analysis. Pulse. 2016 Apr;3(3-4):217-28.

33 Kumar N, Kaur G, Tandon N, Mehra N. Tumor necrosis factor-associated susceptibility to type 1 diabetes is caused by linkage disequilibrium with HLA-DR3 haplotypes. Hum Immunol. 2012;73(5):566-73.

34 Guo X, Li C, Wu J, Mei Q, Liu C, Sun W, et al The association of TNF-alpha -308G/A and $-238 \mathrm{G} / \mathrm{A}$ polymorphisms with type 2 diabetes mellitus: a meta-analysis. Biosci Rep. 2019 Dec 20;39(12):BSR20191301.

35 Ruan QW, Yu ZW, Bao ZJ, Ma YX. The relationship between the polymorphism of immunity genes and both aging and age-related diseases. Yi Chuan. 2013;35(7):813-22.

36 Meyer JM, Han J, Moxley G. Tumor necrosis factor markers show sex-influenced association with rheumatoid arthritis. Arthritis Rheum. 2001 Feb;44(2):286-95. 